\title{
Entre a expectativa e o amadurecimento: a importância da implantação de escritórios de projetos para a gestão pública
}

William Melo; Roberto Nacif; Guilherme Marques e Rodrigo Nippes

\section{Introdução}

Atualmente, a gestão pública brasileira passa por transformações em seus processos internos. Todo o receituário teórico estabelecido por Bresser-Pereira, e também por seus defensores, estabeleceu-se de vez. O governo brasileiro, em seus diferentes níveis federativos, apresenta a nova lógica da modernização da gestão pública, que às vezes atropela o sentido da administração pública, já que se apropria de instrumentos da gestão privada, implementando, assim, práticas completamente alheias à realidade dessas instituições.

Parece evidente que a mudança na nova forma de gerir os interesses públicos apresenta, e apresentará por muito tempo, pontos frágeis. Entretanto, há também a constatação de que novas ferramentas de gestão passam a se adaptar ao modelo característico da gestão pública, podendo ser excelentes instrumentos para o estabelecimento de mecanismos de economicidade, dinamismo e eficiência. Ou seja, os atuais processos de transformação da administração do Estado, ao levantar 
alguns pontos contraditórios nesse processo de adaptação às características da gestão pública, também apresentam alguns pontos que podem ser considerados avanços importantes.

Exemplo disso é a ascensão de projetos especializados na esfera pública, que passaram a utilizar-se da implementação de um referencial teórico que salienta a importância de metodologias de gerenciamento de projetos reconhecidamente respeitadas, o que atualmente torna relevante a abordagem, por parte de estudiosos no tema, de dois pontos em prol da evolução da atual gestão pública: o primeiro refere-se aos escritórios de projetos (Project Management Office - PMO); e o segundo, aos modelos de maturidade organizacional em gestão de projetos. Certamente, o interesse que esses temas têm despertado diz respeito ao fato de que ambos estão relacionados à obtenção de melhores resultados em gerenciamento de projetos, entendendo melhores resultados como a entrega de projetos no prazo, dentro do escopo e do orçamento previstos.

A interpretação comum dos atuais gestores brasileiros é a de que a implementação de Escritórios de Gerenciamento de Projetos (EGP ou PMO), mediante a introdução de uma estrutura formal, auxilia as instituições públicas a melhor gerenciar seus projetos/ações/programas, sejam eles de desenvolvimento de novas políticas públicas/serviços ou de implantação de novos processos, ajudando-as a minimizar os riscos associados e diminuindo os conflitos inerentes às disputas políticas. Prevêse, assim, metodologias adequadas e "isentas" do jogo de poder entre atores públicos. A segunda motivação vem da compreensão de que tais metodologias auxiliam a gestão pública a entender quão imatura se encontra em seus respectivos gerencia- mentos de projetos, buscando confrontar suas ações com estratégias em busca do aprimoramento contínuo no que diz respeito à aquisição de conhecimento, capacidades técnicas e ferramentas, visando a atingir os objetivos da gestão pública ou da agenda governamental por meio de projetos. Portanto, ambos os assuntos tornaram-se importantes na atual gestão pública, pois direta ou indiretamente agora impactam a sociedade e a imagem dos respectivos gestores públicos.

Tudo leva a crer que a gestão pública encontra-se atualmente no interstício do ciclo de maturidade em gerenciamento de projetos em organizações (Frame, 1999; RABECHINI JR, 2003), diante do fato de que o modelo burocrático vem aos poucos perdendo espaço para a efetivação de uma "gestão modernizante", que, automaticamente, traz novas formas de atuação da gestão dos processos de estruturação interna. Se, no passado, a gestão pública se realizava a partir de aptidões e habilidades individuais na solução de problemas, ou na competência de algumas poucas equipes com capacidade de resolução de problemas complexos em contextos multidisciplinares, hoje há a tendência da criação de ambientes que possibilitem o envolvimento tanto do indivíduo quanto das equipes, para que possam realizar seus projetos de forma mais eficaz - implementando e consolidando a importância dos EGP.

Tendo como pressuposto a importância dos atuais modelos de gestão e a absorção de referenciais teóricos de características tão pragmáticas e técnicas, torna-se importante estruturar a reflexão aqui abordada por meio de alguns eixos de análise, apresentando: 1) a importância dos escritórios de gerenciamento de projetos como mecanismos da reforma gerencial do Estado; 2) a metodologia do Project Management Institute 
(PMI) que se insere na realidade de um EGP/PMO, como uma lógica que perpassa a iniciativa privada; e 3) entre a governança e a eficiência: as características presentes na implementação de um EGP/PMO ao deparar-se com as particularidades da gestão pública - o caso do Governo do Estado do Rio de Janeiro.

A importância dos escritórios de gerenciamento de projetos como mecanismos da reforma gerencial do Estado

As reformas da administração do Estado, com o propósito de modernização, não podem ser enquadradas como novidades ou acontecimentos inéditos na história do Brasil. A modernização do Estado, promovida por Getúlio Vargas com a introdução dos princípios da administração burocrática em 1936, por órgãos de elaboração e implementação de políticas para o desenvolvimento, entre eles o Dasp (Departamento Administrativo do Serviço Público), iniciou a mudança da administração patrimonialista que o Estado brasileiro herda de Portugal, em que o Estado era definido como propriedade do respectivo dirigente político, enquanto o patrimônio público se confundia com o privado em uma estrutura baseada em padrões de corrupção e nepotismo. Caracterizou-se, portanto, como um primeiro movimento em prol de uma reforma da gestão pública, combatendo a manipulação dos instrumentos do Estado para alcançar fins privados - a qual promovia a naturalização de frases simbólicas em verdadeiras ações do cotidiano da realidade sociopolítica brasileira, a exemplo de: "Aos amigos, tudo! Aos inimigos, a lei!".

Esse modelo de administração do Estado, exaltado antes do Governo Vargas e enquadrado como um tipo puro de dominação "tradicional" por Max Weber (2008, p. 131), acabará por se mostrar incompatível com a emergência do capitalismo industrial e o processo de desenvolvimento nacional, que viriam a ser implantados após a Revolução de 1930. Tal como afirmado por Weber, o desenvolvimento do Estado moderno "identifica-se com o da moderna burocracia e o da empresa burocrática", assim como "a

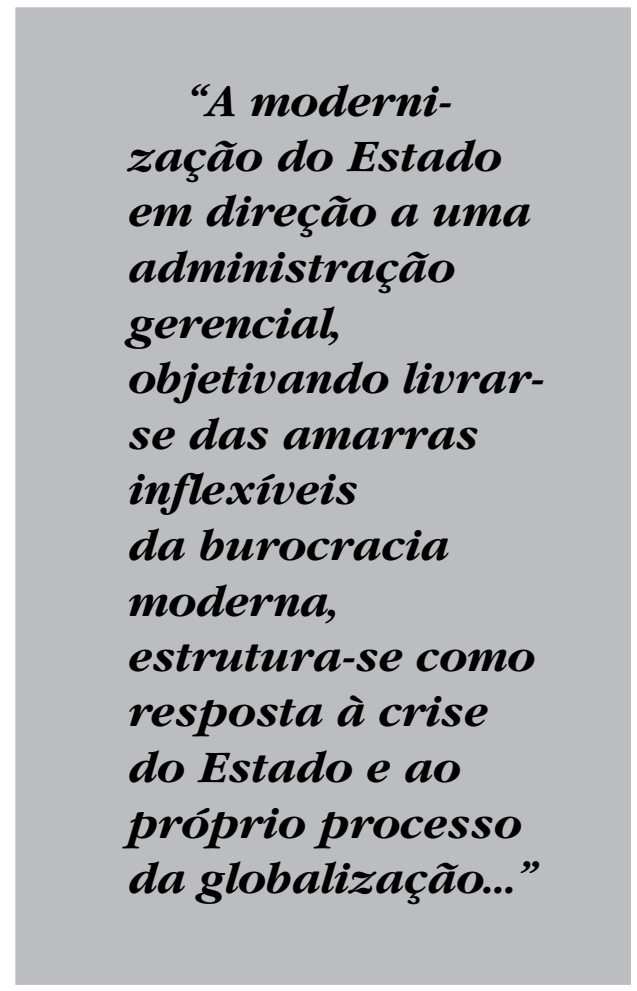

evolução do grande capitalismo moderno se identifica com a burocratização crescente das empresas econômicas" (2008, p. 130). Inicia-se assim um processo de profissionalização dos quadros da administração pública brasileira, bem como a racionalização por meio da administração burocrática moderna ou, nas palavras de Weber, "racional-legal". 
Embora, de fato, tenha se mostrado um modelo de administração do Estado muito superior ao patrimonialista, a emergência do Estado social e econômico do século XX e o número crescente de serviços sociais e econômicos assumidos ${ }^{1}$ acabaram revelando uma administração burocrática lenta, inflexível, cara, voltada exclusivamente para os interesses do aparelho do Estado e, insuficientemente, prestativa e criativa com relação às demandas e pressões sociais. Para além das limitações apontadas, a crise do Estado dos anos 1980 - definida pela crise fiscal ${ }^{2}$, pelo esgotamento da estratégia estatizante de intervenção estatal ${ }^{3} \mathrm{e}$, finalmente, pela crise da forma de administrar o Estado, evidenciada pelas disfunções da burocracia moderna - implicou a necessidade de reformulação e reconstrução da estrutura do Estado, com a pretensão de torná-lo menor, mas, ao mesmo tempo, mais eficiente, barato e voltado para o atendimento das demandas dos cidadãos (BRESSER-PEREIRA, 1996).

Medidas com o intuito de renovar a estrutura básica da administração pública, rumo ao estabelecimento de uma administração direta - composta por órgãos integrantes da Presidência da República e dos ministérios - e de uma administração indireta - constituída por autarquias, fundações, agências reguladoras, empresas públicas e sociedades de economia mista - foram instituídas já em 1967, por intermédio do Decreto-Lei $\mathrm{n}^{\circ} 200$, uma vez que o governo militar estabelecido em 1964 tinha a reforma administrativa como meta (Cavalcanti, 2005). Contudo, a redemocratização do País e o advento da nova Constituição de 1988, viriam novamente a centralizar a administração pública em um movimento de contrarreforma, de modo que a adoção dos princípios gerenciais seria apenas retomada em 1995, durante o Governo Fernando Henrique Cardoso.

A modernização do Estado em direção a uma administração gerencial, objetivando livrar-se das amarras inflexíveis da burocracia moderna, estrutura-se como resposta à crise do Estado e ao próprio processo da globalização, fenômeno que vem ditando a redefinição do papel e das funções do Estado: se a ascensão do capitalismo industrial torna o Estado um protetor das economias nacionais frente à competição internacional, o crescente grau de integração econômica mundial, devido à globalização, demanda do Estado a promoção da economia nacional a um grau de competitividade internacional. Dessa forma, as ideias de descentralização e de flexibilização administrativa vão ganhando espaço em todos os governos, passando a ser adotadas a partir dos anos 1980 por países membros da Organização para Cooperação e Desenvolvimento Econômico (OCDE), a exemplo do Reino Unido, Nova Zelândia, Austrália e países escandinavos, estendendo-se aos Estados Unidos e ao Brasil nos anos 1990. Os principais contornos que estruturam esse novo modelo da administração seriam então:

[...] descentralização do ponto de vista político, transferindo recursos e atribuições para os níveis políticos regionais e locais; (2) descentralização administrativa, através da delegação de autoridade para os administradores públicos transformados em gerentes crescentemente autônomos; (3) organizações com poucos níveis hierárquicos, ao invés de piramidal; (4) pressuposto da confiança limitada e não da confiança total; (5) controle por resultados, a posteriori, ao invés do controle rígido, passo a passo, dos 
processos administrativos; e (6) administração voltada para o atendimento do cidadão, ao invés de autorreferida (Bresser- Pereira, 1996, p. 6).

A proposta de reforma do aparelho do Estado parte, segundo Bresser-Pereira (1996), da existência de quatro setores dentro do Estado: (1) o núcleo estratégico do Estado; (2) as atividades exclusivas de Estado; (3) os serviços não exclusivos ou competitivos; e (4) a produção de bens e serviços para o mercado. Para BresserPereira (1997), a reforma provavelmente significará uma redução do Estado, limitando suas funções no que tange à produção de bens e serviços e, em menor extensão, como regulador. Paralelamente, implicará a ampliação de suas funções no que se refere ao financiamento de organizações públicas não estatais para a realização de atividades consideradas fundamentais e estratégicas, aumentando, assim, a governança ou capacidade de governar; ou seja, a capacidade efetiva do governo de implementar suas políticas, tornando o serviço público ágil, flexível e coerente com a conjuntura atual.

A administração pública gerencial vê o cidadão como contribuinte de impostos e como cliente dos seus serviços. O paradigma gerencial contemporâneo, fundamentado nos princípios da confiança e da descentralização da decisão, exige formas flexíveis de gestão, horizontalização de estruturas, descentralização de funções, incentivos à criatividade (BRASIL, 1995, p. 23)

É evidente que o setor público, em sua busca por eficiência, pode se apropriar de mecanismos de gestão próprios do setor privado, tal como a forma de conduzir e monitorar projetos de modo a gerar uma visão centralizada e precisa a respeito do andamento e da situação de cada um deles. De acordo com Cleland (2002), a adoção de escritórios de gerenciamento de projetos permite a uma organização alcançar a condução de seus projetos da forma mais eficaz e eficiente possível, por meio da consolidação de funções do gerenciamento de projetos, proporcionando a adoção de padrões para itens comuns, como cronogramas e relatórios, além da centralização de informações e outros benefícios derivados de sua estrutura, funções e recursos. Nesse contexto, as principais atribuições do EGP/PMO, segundo Dinsmore (1999), podem ser apontadas tal como demonstrado na figura 1.

Trata-se de um modelo que, apropriado do setor privado, pode ser implementado dentro da estrutura do governo para gestão de projetos emblemáticos baseada em práticas consagradas de gerenciamento de projetos, com o objetivo de melhorar a máquina pública e a atratividade de investimentos privados nacionais e internacionais. Para além desses benefícios, o crescente grau de exigência da sociedade civil, no que tange

\section{Designar recursos para os projetos}

Recrutamento e desenvolvimento de Gerentes de Projetos
Seleção e priorização de projetos
Coordenação dos Gerentes de Projetos

Fonte: Elaboração própria dos autores

Figura 1: Principais atribuições do EGP/PMO 
à eficiência das políticas públicas, vem impulsionando e respaldando a adoção de mecanismos por parte do poder público que resultem na melhor atuação do Estado diante de suas funções.

A forte pressão da sociedade civil também foi outro fator importante, visto que ela se torna cada vez mais exigente e passa a ocupar o status de "cliente do negócio", exigindo melhorias contínuas dos processos públicos institucionais, fruto da inevitável comparação com as estruturas organizacionais do setor privado e do terceiro setor em especial, fazendo com que a administração pública busque a reestruturação dos seus processos e estabeleça um modelo gerencial com foco nos resultados, em substituição progressiva ao modelo administrativo burocrático tradicional, desfocado das suas funções primordiais (PINTo et al, 2009, p. 5)

Demonstra-se, assim, que a adoção de escritórios de gerenciamento de projetos por parte do setor público vai ao encontro dos objetivos da reforma da administração pública, em torno dos princípios determinados pelo modelo gerencial relativos à esfera privada -, focado em resultados e voltado para o atendimento das demandas do cidadão-cliente.

\section{A metodologia do EGP/PMO na administração pública: uma lógica que perpassa a esfera privada}

Passada a euforia difundida pela onda mundial de criação dos PMO, por meio das práticas estabelecidas para o planejamento estratégico de gerenciamento de projetos ${ }^{4}$, difundidas e aplicadas por incontáveis consultores, especialistas em organizar esforços ou ideias de forma lógica, convincente e racional, as organizações públicas ou privadas já não aceitam mais discursos cartesianos repletos de termos importados. Fazendo uma comparação com o setor de informática, poderíamos facilmente nos impressionar com alguém que, no final dos anos 1980, dissesse-nos que "precisaríamos formatar o Hard Disk" ou, então, que recomendasse a troca de pentes de memória RAM. Ouvir, nos dias atuais, de um especialista em planejamento estratégico que "precisamos fazer a análise SWOT" ou que a nossa visão e a missão estão equivocadas, chega a ser algo que quase não demonstra mais as bases de um conhecimento específico adquirido.

Se os PMO instalados nas organizações privadas estão preocupados em justificar sua existência, pois “[...] a cobrança pela geração de valor para um PMO é, de fato, algo muito mais crítico do que a cobrança que normalmente se percebe em áreas de suporte tradicionais, que têm o seu valor traduzido em benefícios nem sempre perceptíveis ou mensuráveis. Ao contrário dessas, um PMO está sendo permanentemente questionado quanto à sua validade e contribuição para a organização, sendo visto muitas vezes como uma espécie de overhead da operação" (PINTO et al, 2010, p. 17); para a gestão pública, essa preocupação ainda não se apresenta. A expectativa atual da esfera pública brasileira é exatamente a adaptação de forma correta dos valores e das práticas contidas em um receituário construído ao longo de décadas, voltado ao privado, e que, por conta de ter obtido êxito em seus propósitos em alguns países, autodenomina-se como genérico e usual para qualquer esfera aplicada. Vejamos se essa autodenominação é possível quando voltamos às suas bases teóricas. 
Após a análise de diversas posições, ressaltamos, como definição geral, que um escritório de gerenciamento de projetos é um local centralizador de atividades ou funções, devendo contribuir, por meio de projetos, para que a organização alcance melhores resultados em seus objetivos, difundindo suas práticas de forma ampla. Apresenta-se aqui a primeira possibilidade de conflito. Em troca de melhores resultados, o PMO pode causar uma perturbação na cultura organizacional do sistema. Em empresas privadas, uma das primeiras ações, quando se elabora um planejamento estratégico sério, consiste em materializar sua identidade corporativa, descrevendo de forma clara e objetiva a cultura organizacional construída. De posse desse documento validado e de uma expectativa de melhora de seus resultados, a alta administração da empresa toma, então, a decisão de deixar ou não, que um PMO interfira em sua cultura. $\mathrm{Na}$ esfera pública, esse processo possui características complexas diversas, que podem levar ao enfraquecimento do PMO antes mesmo de sua criação, como por exemplo, o surgimento de forças políticas de resistências internas e adversas à mudança de cultura organizacional.

Quanto à abordagem, Desouza e Evaristo (2006) identificaram que os papeis de um PMO sempre podem ser classificados em três níveis: estratégico, tático e operacional. O estratégico, ligado à organização como um todo, estaria intimamente relacionado às decisões estratégicas. O nível tático, de assessoramento ao estratégico, promove o aconselhamento e difunde $\mathrm{o}$ que foi estrategicamente deliberado, criando condições para que o operacional realize suas tarefas sem dúvidas quanto ao que deve ser feito.

Quando, na esfera privada, associamos essa classificação com as relações de poder existentes, um PMO pode criar um diagnóstico da situação atual da organização, caso se posicione no nível correto e proponha alterações não ingênuas de melhorias. Na esfera pública, essa classificação é insuficiente para que o PMO entenda sua própria classificação, quando possuímos, por exemplo, em um mesmo nível, funcionários estáveis, prestadores de serviços temporários, autônomos ou cedidos. Além disso, a velocidade com que

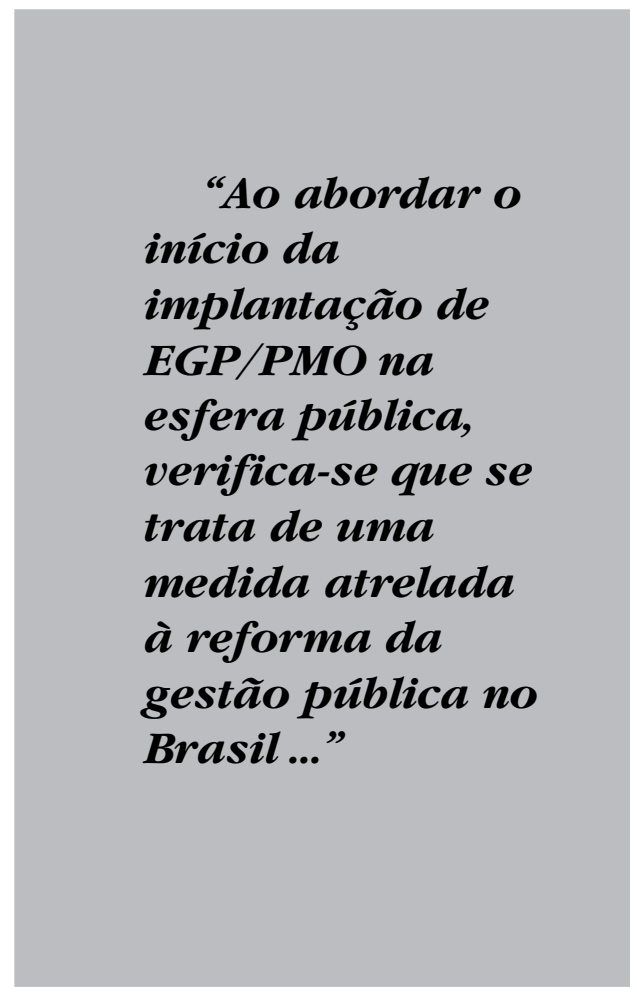

esses níveis se alteram pode ser mais rápida que qualquer tentativa de diagnóstico, causando uma imprecisa e incorreta avaliação. $\mathrm{Na}$ tentativa de amenizar essa crise, que também é observada nas organizações privadas, Englund, Graham e Dinsmore (2003) chegaram a 5 tipos de classificações de PMO: o Single Control Project Office, voltado para apenas um 
projeto, identificando-se com o operacional; o Project Support Office, voltado para toda a empresa, porém identificando-se ainda com o operacional; o Business Unit Project Office, voltado para uma área ou departamento, possuindo identificação estratégica e tática; o Strategic Project Office, voltado para toda a organização, com identificação estratégica; e o Project Management Center of Excellence, com propósito voltado para a inovação. Criou-se, com essa classificação, maior complexidade para o correto posicionamento do PMO.

Após o PMO posicionado, para o seu envolvimento com o ambiente organizacional, utilizaremos a proposta de Assis e Bravim (2008), que apresentam três modelos de escritórios de projetos: a Estação Meteorológica (Weather Station), a Torre de Controle (Control Tower) e a Resource Pool, que chamaremos de Central de Recursos. O modelo denominado como Estação Meteorológica possui a característica principal de monitoramento e apresentação para a alta administração do desempenho dos projetos, introduzindo algumas orientações gerais como a definição de relatórios gerados (periodicidade, formato, ferramentas de elaboração); porém, não exerce influência direta sobre a forma atualmente conduzida para o gerenciamento dos projetos, além de identificar as pessoas e suas práticas. $\mathrm{O}$ modelo Torre de Controle interfere um pouco mais no próprio ambiente na medida em que estabelece padrões e ferramentas de planejamento e gerenciamento, indicando como seguir esses padrões (instruções de voo), realizando aferições e auditorias para constatar se os padrões estão sendo utilizados da forma indicada. No último modelo, Central de Recursos, o PMO possui o conhecimento das melhores práticas para cada caso específico da organização, compartilhando experiências com os diversos gestores de projetos, indicando caminhos com alta chance de sucesso, e principalmente, sendo reconhecido e referendado por quem o utiliza.

Esses modelos podem ser tratados como fases a serem percorridas quando observamos que, na sequência em que foram apresentados, segue-se uma escala de crescimento no que diz respeito ao envolvimento do PMO com a organização. Além disso, tentar pular qualquer uma dessas fases seria mais uma tentativa de adaptação de um receituário pronto, totalmente alheio às características específicas do ambiente organizacional.

[...] Em uma primeira análise, seria possível supor que a maturidade de um PMO deveria evoluir no sentido de ter uma atuação menos operacional e mais estratégica. Entretanto, uma avaliação mais cuidadosa pode nos trazer uma visão diferente do que seria o processo de amadurecimento de um PMO. (PInTo, A. et al, 2010, p. 12)

Sendo assim, temos, a partir de nossa observação, no mínimo quatro expectativas e quatro amadurecimentos distintos: a de quem está implantando a mudança, a de quem está recebendo, a do próprio PMO e, ainda, a do ambiente externo; todas elas se relacionando ao mesmo tempo. Uma situação crítica poderia ser representada por um gestor público imaturo que, criando um PMO em uma de suas secretarias, espera que esse tenha uma abordagem de Project Management Center of Excellence, possua um envolvimento da Central de Recursos e que já inicie suas atividades com um nível avançado de amadurecimento; tudo isso nos primeiros anos de seu mandato. $\mathrm{O}$ que poderia acontecer nesse caso é a transformação do PMO em mais um departamento 
dessa secretaria com a função reduzida de apresentar as contas financeiras dos projetos, por exemplo, uma função básica e fundamental para iniciar suas atividades como Estação Meteorológica. Nessa situação, as relações internas da organização já devem estar provavelmente desgastadas, as expectativas parcialmente ou totalmente frustradas e algumas pessoas já devem estar tentando encontrar meios de justificar a existência do PMO. Da mesma forma, um gestor público amadurecido, que intencionalmente cria uma Estação Meteorológica para colher dados para sua ascensão política dentro da organização, pode estar cultivando a ineficiência e promovendo uma falsa expectativa aos olhos dos outros envolvidos. As consequências geradas a partir de problemas com a relação amadurecimento-expectativa podem desviar o PMO de seus objetivos inicialmente planejados.

As assertivas demonstradas não desabonam essa nova perspectiva para a realidade da gestão pública, já que a gênese e a motivação da adoção de tais práticas, como bem define Heldman (2006), dizem respeito ao escritório de gerenciamento de projetos (EGP) como setor da organização que centraliza, supervisiona e gerencia os projetos e programas da organização; demonstrando-se, com isso, que o EGP pode ser implantado em qualquer organização, em qualquer estrutura, além de funcionar como conselheiro para a alta gestão. Para Dinsmore e Cavalieri (2005) um escritório de gerenciamento de projetos (Project Management Office - PMO) tem como função dar todo suporte para o gerente de projetos, em relação às ferramentas e metodologias aplicadas.

Pinto (2006), por sua vez, acrescenta aos conceitos existentes a ideia de que um EGP deve integrar todas as atividades de gerenciamento de projetos do negócio, de acordo com as estratégias organizacionais, metas e recursos disponíveis que, de certa forma, também se enquadram na realidade organizacional da União, dos Estados ou dos Municípios.

A importância aqui ressaltada visa a demonstrar que as etapas para evolução e desenvolvimento dos $\mathrm{PMO}$ não podem ser negligenciadas ou estabelecidas, mas podem, sim, incorporar a lógica estabelecida na esfera privada, sem desconsiderar as características intrínsecas da administração pública, como bem ressalta Vargas (2012) no quadro a seguir.

O que se observa a partir dos pontos destacados é que a aplicação das práticas de implantação de um escritório de projetos para a gestão pública não pode ser realizada diretamente sem uma profunda adaptação de suas bases conceituais, mas, ao mesmo tempo, também não pode ser implementada a partir de um modelo híbrido que, ao contrário do modelo em vigência na administração privada, não dialogue com todos os possíveis stakeholders da gestão pública.

\section{Governança e eficiência? As características presentes de um EGP/PMO na gestão pública - o caso do Governo do Estado do Rio de Janeiro}

Ao abordar o início da implantação de EGP/PMO na esfera pública, verifica-se que se trata de uma medida atrelada à reforma da gestão pública no Brasil, que, ao ser executada, passa a impactar diretamente duas variáveis muito importantes atualmente: a governança e a eficiência.

Sabendo que essas variáveis conceituais apresentam importância estratégica na atual administração pública e que apresentam 


\begin{tabular}{|c|c|}
\hline Área Privada & Área Pública \\
\hline Faz o que a Lei não proíbe. & Faz o que a Lei permite. \\
\hline Salários compatíveis com o mercado. & Salários inadequados. \\
\hline Maior disponibilidade de pessoal qualificado. & Dificuldade de obtenção de pessoal qualificado. \\
\hline Possível implantar política de incentivo. & Difícil implantar política de incentivo. \\
\hline A estrutura do poder formal é próxima do informal. & $\begin{array}{l}\text { Maior distorção entre o poder formal e o } \\
\text { informal. }\end{array}$ \\
\hline Organização voltada para objetivos. & $\begin{array}{l}\text { Maior incidência de pessoas e segmentos da } \\
\text { organização em desacordo com os objetivos. }\end{array}$ \\
\hline $\begin{array}{l}\text { Alta administração sofre cobrança permanente } \\
\text { quanto a objetivos e metas a serem atingidos. }\end{array}$ & $\begin{array}{l}\text { A cobrança da sociedade é de caráter mais } \\
\text { subjetivo e geral. }\end{array}$ \\
\hline Continuidade administrativa mais permanente. & $\begin{array}{l}\text { Maior risco quanto à quebra da continuidade } \\
\text { administrativa. }\end{array}$ \\
\hline $\begin{array}{l}\text { Pouco frequente a paralisação de programas } \\
\text { e projetos por falta de recursos. }\end{array}$ & $\begin{array}{l}\text { Frequentemente ocorre paralisação de } \\
\text { programas e projetos por falta de recursos. }\end{array}$ \\
\hline $\begin{array}{l}\text { Decisão quanto aos objetivos centrada em } \\
\text { poucos órgãos. }\end{array}$ & Maior dispersão quanto à tomada de decisão. \\
\hline $\begin{array}{l}\text { Familiaridade com as ferramentas de } \\
\text { planejamento e controle. }\end{array}$ & $\begin{array}{l}\text { Pouca tradição no uso das ferramentas de } \\
\text { planejamento e controle. }\end{array}$ \\
\hline $\begin{array}{l}\text { Impulsionada pela competitividade, baixo grau de } \\
\text { consciência quanto à realidade da competição. }\end{array}$ & Presença marcante da burocracia. \\
\hline Voltada para a qualidade. & Conceito de qualidade ainda incipiente. \\
\hline
\end{tabular}

Fonte: Vargas (2012).

múltiplas interpretações, inicio a questão ressaltando a importância de demonstrar o tipo de conceituação que aqui será abordada, indicando que, ao falar de governança, queremos ressaltar que se trata de:

[...] uma nova geração de reformas administrativas e de Estado, que têm como objeto a ação conjunta, levada a efeito de forma eficaz, transparente e compartilhada pelo Estado, pelas empresas e pela sociedade civil, visando uma solução inovadora dos problemas sociais e criando possibilidades e chances de um desenvolvimento futuro sustentável para todos os participantes. (LofFer apud KISSLER et al., 2006, p. 482).

Sob a ótica dos presentes autores deste trabalho, a governança pública preconizada e atualmente inscrita na realidade política brasileira está intimamente ligada à mudança na gestão pública. Trata-se de uma tendência de se recorrer cada vez mais à autogestão nos campos social, econômico 
e político, e a uma nova composição de formas de gestão daí decorrentes. Paralelamente à hierarquia e ao mercado, com suas formas de gestão à base de "poder e dinheiro", ao novo modelo somam-se intensos processos de negociação.

Sendo assim, a governança aqui analisada é entendida como uma alternativa à gestão baseada na hierarquia. Esta, em relação à esfera local, significa que as cidades fortalecem cada vez mais a cooperação com os cidadãos, as empresas e as entidades sem fins lucrativos na condução de suas ações. A cooperação engloba tanto o trabalho conjunto de atores públicos, comunitários e privados, como também novas formas de transferência de serviços para grupos privados. A governança pública é, assim, "uma forma autônoma (self-organižing) de coordenação e cooperação, por meio de redes interorganizacionais, que podem ser formadas por representantes de organizações políticas e administrativas, associações, empresas e sociedades civis, com ou sem a participação estatal" (JANN, apud KISSLER et al., 2006, p. 483).

Essas mudanças, ocorridas a partir da movimentação das reformas na administração pública e da inserção de uma governança que delega a ação estatal a um papel cada vez mais secundário, também afetam os princípios da eficiência nos serviços públicos, que passa por significativas alterações, ganhando ainda mais flexibilidade e novas características.

Se a eficiência consiste em buscar com objetividade melhores resultados com menor dispêndio, tornando os serviços públicos mais baratos e, portanto, mais acessíveis a toda a sociedade, coibindo o mau gasto do dinheiro público (Bandeira De Mello, 2007), é importante refletir, no entanto, que a prática encontra-se distante do ideal.
Ao se aprofundar no estudo das mudanças advindas dos processos da reforma da administração pública no Brasil, verifica-se uma constante presença de características de uma gestão atrasada - esta continua estabelecendo esquemas de corrupção, propinas e malversação dos recursos públicos -, que contrariam e impedem a aplicação dos princípios constitucionais da eficiência pública brasileira, tendo como uma de suas motivações de existência

"O tema se

torna relevante

pelo fato de

possibilitar, de

forma pioneira, a implementação de medidas de adoção de uma metodologia padronizada para todas as ações dos governos ..."

o favorecimento a instituições e personalidades influentes que, fortalecidas por uma concepção contraditória de governança, interferem nas gestões públicas estabelecendo práticas de alteração das culturas, programas, projetos, políticas públicas e organizações, a partir de modelos academicamente distantes da realidade organizacional da administração pública brasileira - fato presente, por exemplo, na 
incorporação de diferentes consultorias e auditorias nos mais diferentes momentos estratégicos dos governos.

Entretanto, é importante salientar que tal assertiva não dá conta de todas as novas estruturas do novo modelo de gestão pública. É preciso ressaltar que tal referência teórica, ao mesmo tempo em que estabelece práticas verticalizadas e atrasadas, também possibilita a exaltação de metodologias e ações que, em sua gênese, tendem a questionar e enfraquecer as ações anteriormente criticadas, como parece ser o caso da implementação de EGP ou PMO nos diferentes órgãos públicos. Assim, os males ocasionados por uma mudança na gestão pública brasileira trazem, por sua vez, possibilidades reais de alteração do modus operandi de elaborar, executar, fiscalizar e acompanhar as mais diferentes ações do Estado, possibilitando, ao menos em tese, um caminho que volta a privilegiar princípios de eficiência, economicidade, transparência etc.

Ao exaltar a implementação de EGP/ PMO como novas estruturas nos órgãos públicos, não há, por parte desses autores, a ingenuidade de creditar a esses novos desenhos organizacionais um modelo que transforme radicalmente o cenário do setor estatal, ou que seja incorruptível e probo por excelência. O que queremos salientar, por sua vez, é a possibilidade de que os órgãos públicos passem a ter, ao implementarem pela primeira vez dentro de suas estruturas organizacionais, um órgão que poderá - ou, em tese, apresenta em sua gênese esse potencial - padronizar as ações do Estado, estabelecendo metodologia e indicadores reconhecidamente compreensíveis para qualquer gestor, seja da esfera pública ou privada. O tema se torna relevante pelo fato de possibilitar, de forma pioneira, a implementação de medidas de adoção de uma metodologia padronizada para todas as ações dos governos, dando importância tanto para a administração direta quanto para a administração indireta; o que levaria à evidência de uma das ações mais propensas à retórica de gestão pública de forma moderna e eficiente, que é tão exaltada por políticos e estudiosos da área, mas que ainda não se percebe na prática da gestão pública brasileira.

A implementação de EGP/PMO na gestão pública, de fato, apresenta-se com potencial de modificar e inovar a administração pública, uma vez que possibilita um novo cenário onde as ações estatais são realizadas a partir do planejamento, programação e controle de uma série de tarefas integradas que, trabalhadas conjuntamente, visam a atingir os objetivos dos governos como empreendimentos atrelados aos respectivos recursos, operando sob a lógica das pressões de prazos, custos e qualidade dos serviços públicos (KERZner, 2002). Essas novas abordagens, que, de antemão, podem parecer distantes da realidade da administração pública brasileira, passam, pouco a pouco, a serem observadas e incluídas pelos respectivos gestores públicos de forma menos desconfiada, o que demonstra uma propensão para adoção de metodologias como as do Project Management Institute (PMI). Ou seja, de maneira isolada, algumas prefeituras e governos estaduais brasileiros vêm adotando a implantação de EGP/PMO, utilizando-se desses escritórios como instrumentos de gestão em prol da modernização da administração pública, com foco na prestação de serviços públicos primordiais, como o que parece ocorrer nas ações estratégicas do Governo do Estado do Rio de Janeiro.

No caso do governo carioca, o EGP do Rio de Janeiro é de importância 
estratégica, além de gerenciar os projetos estruturantes, a responsabilidade pela gestão de interesses prioritários da administração pública estadual, já que administra os convênios realizados pelo Estado. Dessa forma, o EGP/PMO instituído na administração pública do Governo do Estado do Rio de Janeiro tem não apenas um papel de controlador, mas, preferencialmente, de órgão com clara definição do que deve ser controlado para alcance das metas estabelecidas pela gestão pública. Sendo assim, verificam-se nestes quase cinco anos de implantação do EGP/PMO - o Decreto 40.890, de criação da EGP-Rio, foi assinado em 08 de agosto de 2007 - os seguintes benefícios referentes aos projetos estruturantes: i) garantia da conclusão dos projetos; ii) execução físico-financeira dos projetos, conforme o planejamento estabelecido; iii) promoção da maior visibilidade do andamento dos trabalhos.

Corrobora-se, assim, a disseminação do conhecimento em gerenciamento de projetos por toda estrutura organizacional do governo, o que, por sua vez, possibilita a implementação de ações com a finalidade de aperfeiçoamento contínuo, já que permite: i) a profissionalização da gestão dos projetos, ações, programas e políticas públicas do governo; ii) o aumento da garantia de cumprimento de prazos e custos e; iii) a possibilidade do alcance das metas dos projetos, a partir de maiores mecanismos de transparência e de informações em tempo real.

Sendo assim, no estudo de caso analisado, a metodologia do EGP-Rio está fielmente aderente ao modelo do Project Management Body of Knowledge (PMBOK do PMI), anteriormente citado e defendido como metodologia ideal para implantação de um EGP/PMO - sendo ainda vinculada a ISO-10006 -, baseado no modelo de melhoria contínua do ciclo de PDCA (Plan/Do/Check/Act), para cumprimento das metas de profissionalização da gestão por projetos, tendo como foco a eficácia na execução dos projetos e a visibilidade e transparência para todos os stakeholders.

O EGP-Rio, ao ser criado, assumiu como uma de suas principais finalidades o compromisso de vencer o desafio de profissionalizar a gestão pública do Estado do Rio de Janeiro. Sua estrutura, além de possibilitar o monitoramento de projetos estruturantes, também passa a capacitar os gerentes dos projetos, buscando tornar-se referência nacional na gestão dos diversos convênios firmados pelo Governo do Estado do Rio de Janeiro. Seu diferencial, em relação às outras estruturas internas de outros governos, é que o EGP-Rio orienta-se diretamente aos projetos estratégicos da agenda governamental, o que possibilita que esse órgão não seja um mero revisor das ações estatais, mas, sim, um parceiro na definição de ações em longo prazo, como fica evidenciado na importância hierárquica obtida pelo EGP no organograma da Secretaria da Casa Civil do Estado do Rio de Janeiro (Figura 2).

O EGP-Rio está diretamente focado no processo destinado à criação, remodelagem e manutenção das políticas internas na estrutura organizacional do ambiente da Secretaria da Casa Civil do Estado do Rio de Janeiro, o que, de certa forma, possibilita que, ao longo do tempo, o EGP-Rio passe a exercer o papel de coordenação de todos os projetos emblemáticos do plano estratégico da agenda de governo, tendo como macroatribuição o monitoramento, o acompanhamento e a comunicação das informações de todos os projetos financiados ou em parcerias com o governo do estado. 


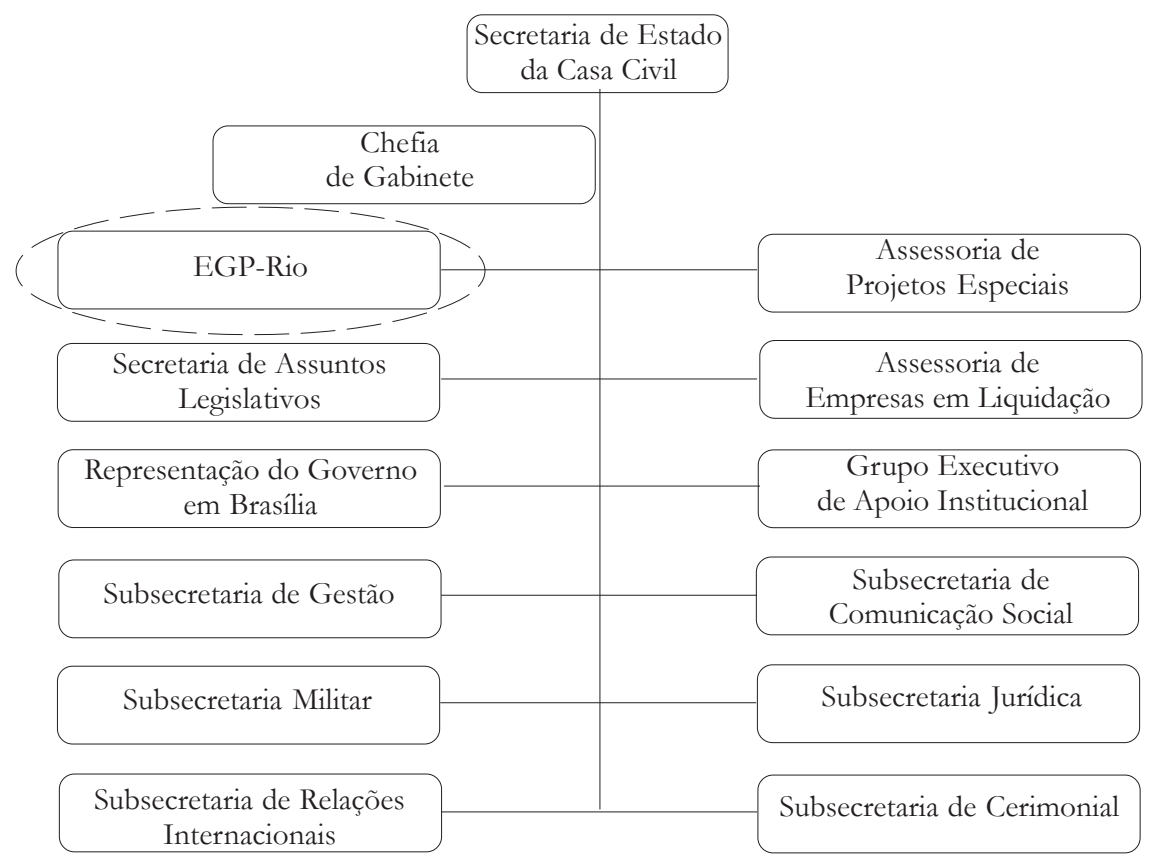

Fonte: Portal do EGP-Rio, 2012.

Figura 2: Organograma da Secretaria de Estado da Casa Civil do Governo do Rio de Janeiro

Ao se efetivar como órgão de vital importância na estrutura organizacional do governo, o EGP-Rio possibilitou a padronização das normas e procedimentos por meio da customização de modelos, com foco na criação e atualização de um repositório de documentos para a efetivação de processos, formulários, melhores práticas e padrões a serem replicados, sendo, inclusive, responsáveis pela melhoria contínua.

Suas ações possibilitam revisões e análises dos projetos nos quesitos de qualidade e desempenho, e desenvolvem, por assim dizer, a função de servir à alta administração como ponto único de controle e informação de todos os projetos do portfólio de ações estratégicas estruturantes do Estado do Rio de Janeiro, fornecendo: i) visão macro do portfólio de projetos estruturantes do governo; ii) visão financeira dos projetos; iii) visão da qualidade dos projetos - dando ênfase a atendimento de requisitos, satisfação da sociedade e indicadores de desempenho. Todas as características dos EGP/PMO colocam-se como novos marcos para a administração pública brasileira, pois esses novos órgãos, acompanhados de metodologias que estão calcadas na construção de indicadores de desempenho e na busca de melhoria contínua, passam a orientar-se na melhoria das gestões de contratos de convênios, criando grupos de gestores que ajudam na melhoria da captação de recursos extratesouro (sejam verbas provenientes do governo federal ou de instituições multilaterais), e dando 
aos estatutários e demais colaboradores da gestão pública a possibilidade de capacitações com a finalidade de melhorar a gestão e o controle dos recursos públicos. O que torna essa ação não apenas mais uma medida modernizante, senão vital para uma administração pública contemporaneamente carente de gestões técnicas e calcadas no interesse público (figura 3).

\section{Considerações finais}

A partir do exposto, pode-se perceber que houve mudanças substanciais que marcaram as duas últimas décadas no mundo, especialmente no que se refere ao reordenamento das relações entre Estado e sociedade. Fica nítida uma reflexão sobre as mudanças ocorridas no Estado, principalmente quando se trata de seu padrão intervencionista de garantir o chamado "bem-estar social" e da garantia de um padrão de "eficiência" para gerar à população retorno de bens e serviços.

Percebe-se, também, que o discurso pautado pela eficiência, eficácia, modernidade e transparência tornou-se elemento essencial nesse processo de reestruturação governamental e administrativa, que justifica o redirecionamento da gestão da máquina estatal.

As iniciativas pioneiras tomadas nesse sentido foram implementadas a partir de reformas em determinadas secretarias estaduais, municipais e na União, redesenhando-se os modelos de gestão em que as palavras de ordem passaram a ser enxugamento, modernidade, eficiência e fusões.

Além disso, foram retrabalhados os cargos comissionados e realizadas alterações visando à eficácia do planejamento e da gestão dos próprios órgãos da administração pública, e ao controle eficaz das ações e dos gastos efetuados pelos agentes públicos.

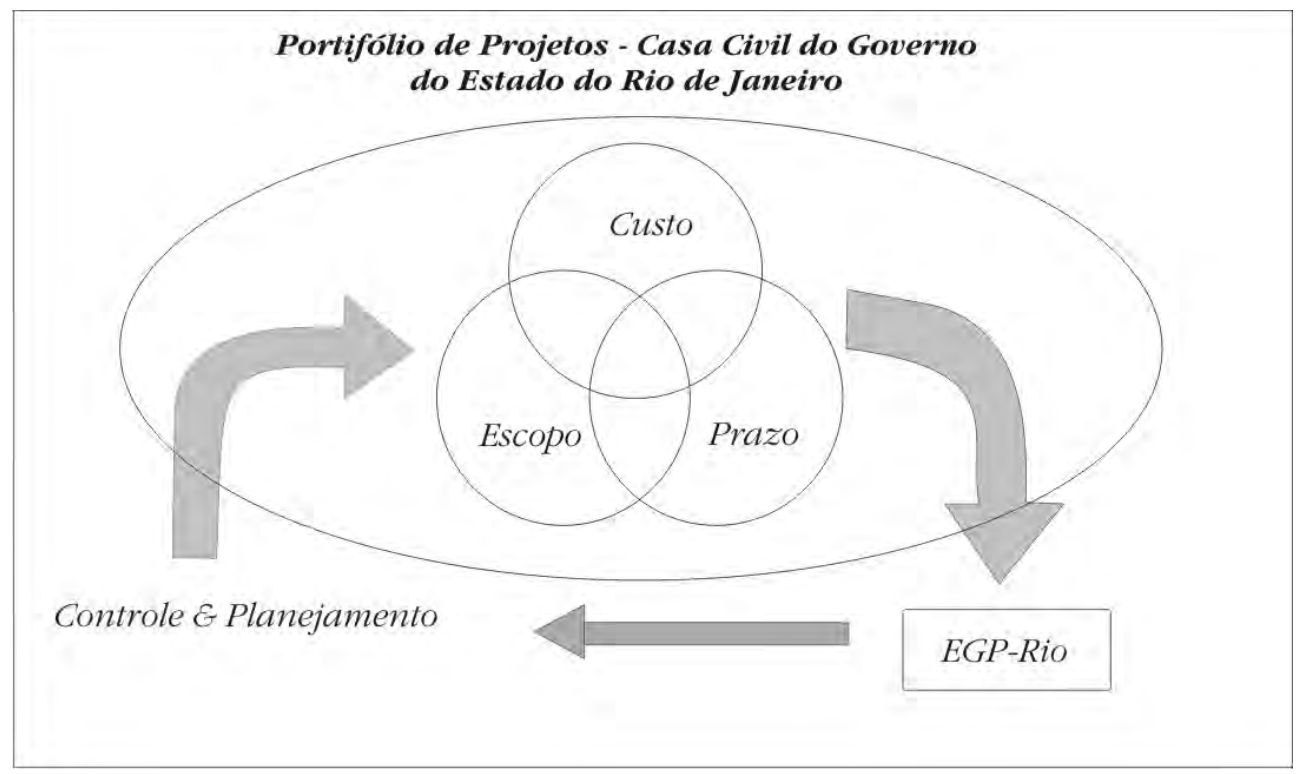

Fonte: Elaboração própria dos autores.

Figura 3: Metodologia de gerenciamento de projetos do EGP-Rio 
As críticas às ineficiências do sistema burocrático de governo também contribuíram sobremaneira para a instauração de uma nova lógica administrativa pautada em critérios advindos do setor privado, em que a análise do desempenho de pessoas e instituições torna-se elemento-chave. A chamada "cultura do desempenho" é assim garantida a partir da criação do Estado avaliador.

Para o interesse específico desse trabalho, mereceram atenção dois pontos principais: o primeiro refere-se aos escritórios de projetos (Project Management Office - PMO) e sua atuação na gestão pública (mais especificamente no EGP-Rio); e o segundo, aos modelos de maturidade organizacional em gestão de projetos.

No Brasil, o chamado modelo gerencial ganha destaque primeiramente no (breve) Governo Collor de Melo, mas é consubstanciado no Governo Fernando Henrique Cardoso, ganhando status de ministério com o Ministério da Administração Federal e Reforma do Estado (Mare), em que o ministro Luiz Carlos Bresser-Pereira tornou-se titular da pasta. Trata-se de um movimento que é portador de um novo modelo de administração pública, baseado no estabelecimento de alianças estratégicas entre Estado e sociedade, quer para atenuar disfunções operacionais da parte do Estado, quer para maximizar os resultados da ação social em geral (MARE, 1997).

Sendo assim, a implantação de EGP na administração pública, como se evidencia no modelo do Governo Estadual do Rio de Janeiro, objetiva agregar e abranger todos os conceitos difundidos no ramo da gestão de projetos, tendo, subsidiariamente, a preocupação de detalhar etapas do planejamento e acompanhamento do escritório. Isso fica evidente ao se observarem os sistemas de estruturação desenvolvidos, por exemplo, no EGP-Rio, que englobam conceitos e modelos atuais para a gestão dos projetos, todos condizentes com os recentes modelos teóricos defendidos para a gestão pública.

Logicamente, a adoção desses novos modelos de gestão apresenta obstáculos para sua efetiva implementação. São barreiras vinculadas à cultura organizacional do governo do estado, à dificuldade de inclusão da alta administração nos processos de implantação das EGP, e, também, à dificuldade de adaptação da estrutura organizacional a uma matriz flexível, que é imprescindível para o bom funcionamento do modelo de gerenciamento proposto.

É importante salientar que as administrações públicas ainda estão em processo de experiência em relação a implementações de PMO, uma vez que tal processo está fatalmente ligado à capacidade dos gestores de adaptar o modelo de PMO, que segue o referencial metodológico da reforma da gestão pública. Assim, flexibilizam suas ações para, enfim, obterem êxito na evolução da mudança cultural dos atores públicos em relação à máquina governamental e para se manterem como órgãos funcionais e adaptados ao caráter de eficiência prevista em nosso direito constitucional; ao contrário de uma eficiência de caráter administrativo que serve aos PMO em instituições privadas, mas que não faz qualquer sentido no espaço estatal e na gestão da "coisa pública".

O que este paper tentou evidenciar foi a importância dos PMO na realidade contemporânea dos governos, demonstrando que tal iniciativa apresenta alguns obstáculos para seu real desenvolvimento, já que a gestão pública apresenta características intrínsecas. Ao expor os desafios desse novo órgão na estrutura organizacional de alguns governos, os autores tiveram a intenção de ressaltar os interesses positivos em relação 
aos PMO, por acreditar que tais ações, de certo modo, possibilitam um avanço em prol de ações do Estado menos particularistas e de caráter privado, e a retirada definitiva da influência de instituições e atores privados em relação ao pseudomonopólio sobre conhecimentos, teorias e metodologias de planejamento estratégico e de projetos, que atualmente tornaram-se bons argumentos a favor de ineficientes gastos públicos que favorecem apenas pequenos interesses particulares, sendo muitas vezes não efetivados na realidade pública cotidiana.
Atualmente, a retórica da "enorme ineficiência estatal", na qual o Estado brasileiro já não atenderia com eficiência a sobrecarga de demandas a ele dirigidas, pode ser alterada, caso ações como a dos PMO sejam seriamente executadas, possibilitando à sociedade, aos estudiosos, aos gestores públicos e aos demais interessados um novo desafio que, peremptoriamente, necessitará de amadurecimento e que fatalmente gerará inúmeras expectativas.

(Artigo recebido em agosto de 2012. Versão final em dezembro de 2012).

\section{Notas}

${ }^{1}$ Entre tais serviços assumidos, destacam-se, na esfera social: a educação, a saúde, a cultura, a previdência, a assistência social e a pesquisa científica. Na esfera econômica, pode-se citar: a regulação do sistema econômico interno e das relações econômicas internacionais, a estabilidade da moeda e do sistema financeiro, a provisão de serviços públicos e de infraestrutura.

${ }^{2}$ Caracterizada pela crescente perda do crédito por parte do Estado e pela poupança pública que se torna negativa.

${ }^{3}$ Entre as quais, a crise do Estado do bem-estar social, a estratégia de substituição de importações e o estatismo nos países comunistas.

${ }^{4}$ Projeto é um esforço temporário empreendido para criar um produto, serviço ou resultado. E gerenciamento de projetos é a aplicação de conhecimentos, habilidades, ferramentas e técnicas às atividades do projeto, a fim de atender aos seus requisitos (PMI, 2004).

\section{Referências}

Assis, J. P.; Bravim, V. PMO: implantando o escritório de projetos. Vitória, ES: CoMPET PM - Treinamento e Consultoria, 2008.

Bandeira de Mello, Celso Antônio. Curso de direito administrativo. 23. ed. São Paulo: Malheiros Editores, 2007.

Brasil. Plano diretor da reforma do aparelho do Estado. Brasília: Presidência da República, Câmara da Reforma do Estado, Ministério da Administração Federal e Reforma do Estado, 1995. 
- Ministério da Administração Federal e da Reforma do Estado (MARE). Plano de Reestruturação e Melhoria da Gestão do MARE. Brasília: MARE, 1997.

Bresser-Pereira, Luis Carlos (1996). Da administração Pública Burocrática à Gerencial. Revista do Serviço Público, Brasília, n. 47.

. Estratégia e estrutura para um novo Estado. Revista de Economia Política, v. 17, n. 3 (67), 1997.

Cleland, David I. \& Ireland, Lewis R. Gerência de Projetos. Rio de Janeiro: Reichmann \& Affonso, 2002.

Desouza, K. C., \& Evaristo, J. R. Project Management Offices: a case of knowledge-based archetypes. International Journal of Information Management, 26, 414-423, 2006.

Dinsmore, Paul C. Winning in business with enterprise project management. New York: Amacom, 1999.

Dinsmore, Paul. C.; Cavalieri, A. Como se tornar um profissional em Gerenciamento de Projetos: Rio de Janeiro, Qualitymark, 2005.

EGP-Rio. Disponível em: http://www.egprio.rj.gov.br. Acessado em: 17/07/2012.

Englund, R. L.; Graham, R. J., \& Dinsmore, P. C. Creating the Project Office - A Manager's Guide to Leading Organizational Change. San Francisco: Jossey-Bass, 2003.

Frame, J. D. Project management competence: building key skills for individuals, teams, and organizations. San Francisco: Jossey-Bass, 1999.

Heldman, K. Gerência de projetos. Rio de Janeiro: Elsevier, 2006.

Kerzner, H. Project Management: a systems approach to planning, scheduling and controlling. 8 Ed. New York: John Wiley \& Sons, 2002.

Kissler, Leo; Heidemann, Francisco G. Governança pública: novo modelo regulatório para as relações entre Estado, mercado e sociedade? Revista de Administração Pública RAP, Rio de Janeiro, 40(3):479-99, maio/jun., 2006.

Pinto, A.; CotA, M. F; Levin, G. PMO Maturity Cube: um modelo de avaliação de maturidade exclusivo para escritório de projetos. Revista Mundo PM, Ano 06, n. 35, nov., 2010. PINTO, Analia \& SILVA, Wainer.A utilização de escritórios de gerenciamento de projetos na gestão da administração pública. Um estudo de caso: Governo do Estado do Rio de Janeiro. In: II Congresso Consad de Gestão Pública, 2009. Brasília.

PINTO, A. Escritório de Projetos e Modelos de Maturidade. Rio de Janeiro, 2006. Disponível: em: <http://www.americopinto.com.br/biblioteca.asp>. Acesso em: 18 mar. 2009.

Rabechini J. R., Roque. Competências e maturidade em gestão de projetos: uma perspectiva estruturada. 2003. Tese (Doutorado) — Departamento de Engenharia de Produção da Escola Politécnica da Universidade de São Paulo, São Paulo, São Paulo, Brasil.

VARGAS, Ricardo. (2012) Disponível em: < http:// wmw.ricardo-vargas.com/pt/>. Acesso em: 20 set. 2012.

WeBER, M. Die drei reinen Typpen der legitimem Herrschaft. In: Wirtschaft und Gesellschaft. 4. ed.. Organizada e revisada por Johannes Winkelmann. Tubingen, J.C. B. Mohr (Paul Siebeck), v. II, p.551-58, 1956. Tradução de Gabriel Cohn. In: WEBER, Max. Sociologia. Coleção grandes cientistas sociais, n. 13. São Paulo: Ática, 1979. 


\section{Resumo - Resumen - Abstract}

\section{Entre a expectativa e o amadurecimento: a importância da implantação de escritó- rios de projetos para a gestão pública William Melo; Roberto Nacif; Guilherme Marques e Rodrigo Nippes}

Este trabalho analisa um fenômeno presente no cenário da administração pública brasileira: a implementação de PMO nas estruturas organizacionais dos governos brasileiros. A incorporação desses métodos, oriundos da gestão privada, incorporados atualmente à administração pública, interfere no processo de produção de novas políticas públicas e formas de gestão. Para tanto, contextualizamos essa ação a partir da consideração de que, a partir do fim dos anos 1980 e início da década de 1990, instauram-se novos tipos de ordenamentos nas relações entre os aparelhos do Estado, a sociedade no Brasil e os gestores públicos brasileiros, questionando-se a excessiva gama de funções do Estado e sua real eficiência. Essas novas metodologias adotadas apontam novas estratégias de gestão e possibilidades ao Estado, como ilustradas no caso da implementação do EGP no Governo do Rio de Janeiro. Estabelece-se, assim, uma solução inovadora dos problemas sociais, criando possibilidades e chances de um desenvolvimento sustentável para toda a sociedade.

Palavras-chave: Reforma do Estado; administração pública; escritórios de gerenciamento de projetos

Entre la expectativa y la maduración: la importancia de la implantación de las oficinas de proyectos para la gestión pública

William Melo; Roberto Nacif; Guilherme Marques y Rodrigo Nippes

Este trabajo examina un fenómeno presente en el escenario de la administración pública brasileña: la implementación de PMO en las estructuras organizativas de los gobiernos de Brasil. Estos métodos, con origen en la gestión privada y ahora incorporados en la administración pública, interfieren en el proceso de producción de nuevas política públicas y formas de gestión. En este sentido, contextualizamos esta acción a partir de la consideración de que, desde fines de los 80 y principios de la década de 1990, se establecen nuevos tipos de órdenes en las relaciones entre los aparatos de Estado, la sociedad en Brasil y los gestores públicos brasileños, a partir de lo que se cuestiona la excesiva gama de funciones del Estado y su eficacia real. Estas nuevas metodologías adoptadas apuntan nuevas estrategias de gestión, estableciendo nuevas posibilidades para el Estado, como se ilustra en el caso de la implementación de la EGP en gobierno de Rio de Janeiro. Se establece, por lo tanto, una solución innovadora a los problemas sociales, creando oportunidades y posibilidades de un desarrollo sostenible para toda la sociedad.

Palabras clave: Reforma del Estado; administración pública; oficinas de gestión de proyectos

\section{Between expectation and maturation: the importance of project offices for public management \\ William Melo; Roberto Nacif; Guilherme Marques and Rodrigo Nippes}

This paper examines a phenomenon currently present in the scenario of the Brazilian public administration: the implementation of PMO's in the organizational structures of some Brazilian governments. The incorporation of these methods from the private management, now incorporated into the government interfere directly in the process of production of new policies 
and ways of managing. For this purpose, we contextualize this action from the consideration that from the late '80s and early 1990s are established new types of ordering in relations between the apparatus of state, the society in Brazil and the Brazilian public managers by which is questioned the excessive range of functions of the state and its real efficiency. These new methodologies adopted shows new management strategies, providing new possibilities to the State, as illustrated in the case of the implementation of the PMO in the government of Rio de Janeiro. It's established, in this way, an innovative solution of social problems, creating opportunities and chances for a sustainable development for the whole society.

Keywords: State Reform; public administration; project management offices

\section{William Melo}

Mestre em Administração Pública pela Fundação Getúlio Vargas (FGV). É professor na Universidade Federal Rural do Rio de Janeiro (UFRRJ), no Centro Federal de Educação Tecnológica do Rio de Janeiro (CEFET/RJ), na FGV-Rio e consultor/ controller na FGV Projetos. E-mail: willian.melo@fgv.br.

\section{Roberto Nacif}

Mestre em Administração Pública pela Fundação Getúlio Vargas. É professor e consultor na Universidade do Estado do Rio de Janeiro (UERJ). E-mail: rbnacif@yahoo.com.br.

Guilherme Marques

Bacharel em Ciências Sociais pela Fundação Getúlio Vargas e trainee da Diretoria Internacional da referida Fundação. Email: guimarques@hotmail.com.

Rodrigo Nippes

Mestre em Sociologia Política pela Universidade Federal de Santa Catarina (UFSC) e consultor na FGV Projetos. E-mail: rodrigonippes@yahoo.com.br. 